\title{
SCIENTIFIC REPORTS

\section{Rhizodegradation of Petroleum Oily Sludge-contaminated Soil Using Cajanus cajan Increases the Diversity of Soil Microbial Community}

\author{
Ibrahim Alkali Allamin $\mathbb{D}^{1,2}$, Mohd Izuan Effendi Halmi ${ }^{3}$, Nur Adeela Yasid ${ }^{1}$, \\ Siti Aqlima Ahmad ${ }^{1}$, Siti Rozaimah Sheikh Abdullah ${ }^{4}$ \& Yunus Shukor $\mathbb{1}^{1 *}$
}

Most components of petroleum oily sludge (POS) are toxic, mutagenic and cancer-causing. Often bioremediation using microorganisms is hindered by the toxicity of POS. Under this circumstance, phytoremediation is the main option as it can overcome the toxicity of POS. Cajanus cajan a legume plant, was evaluated as a phyto-remediating agent for petroleum oily sludge-spiked soil. Culture dependent and independent methods were used to determine the rhizosphere microorganisms' composition. Degradation rates were estimated gravimetrically. The population of total heterotrophic bacteria (THRB) was significantly higher in the uncontaminated soil compared to the contaminated rhizosphere soil with C. cajan, but the population of hydrocarbon-utilizing bacteria (HUB) was higher in the contaminated rhizosphere soil. The results show that for 1 to $3 \%$ oily sludge concentrations, an increase in microbial counts for all treatments from day 0 to $90 \mathrm{~d}$ was observed with the contaminated rhizosphere CR showing the highest significant increase $(p<0.05)$ in microbial counts compared to other treatments. The metagenomic study focused on the POS of $3 \%(w / w)$ and based on the calculated bacterial community abundance indices showed an increase in the values for Ace, Cho, Shannon (Shannon-Weaver) and the Simpson's (measured as InvSimpson) indices in CR3 compared to CN3. Both the Simpson's and the Shannon values for CR3 were higher than CN3 indicating an increase in diversity upon the introduction of $C$. cajan into the contaminated soil. The PCoA plot revealed communitylevel differences between the contaminated non-rhizosphere control and contaminated rhizosphere microbiota. The PCoA differentiated the two treatments based on the presence or absence of plant. The composition and taxonomic analysis of microbiota-amplified sequences were categorized into eight phyla for the contaminated non-rhizosphere and ten phyla for the contaminated rhizosphere. The overall bacterial composition of the two treatments varied, as the distribution shows a similar variation between the two treatments in the phylum distribution. The percentage removal of total petroleum hydrocarbon (TPH) after 90 days of treatments with 1, 2, 3, 4, and $5 \%$ (w/w) of POS were 92, 90, 89, 68.3 and $47.3 \%$, respectively, indicating removal inhibition at higher POS concentrations. As the search for more eco-friendly and sustainable remediating green plant continues, $C$. cajan shows great potential in reclaiming POS contaminated soil. Our findings will provide solutions to POS polluted soils and subsequent re-vegetation.

\footnotetext{
${ }^{1}$ Department of Biochemistry, Faculty of Biotechnology and Biomolecular Sciences, Universiti Putra Malaysia, 43400 UPM Serdang, Selangor, Malaysia. '2Department of Microbiology, Faculty of Sciences, University of Maiduguri, P.M.B. 1069, Maiduguri, Borno State, Nigeria. ${ }^{3}$ Department of Land Management, Faculty of Agriculture, University Putra Malaysia, 43400 Serdang, Selangor, Malaysia. ${ }^{4}$ Department of Chemical and Process Engineering, Faculty of Engineering and Built Environment, Universiti Kebangsaan Malaysia, UKM Bangi 43600, Selangor, Malaysia. *email: mohdyunus@upm.edu.my
} 
The global over-dependent on fossil fuels as sources of energy increases the rate and extent of exploration, transportation, refining and storage of crude oil by the petroleum industries ${ }^{1,2}$. Petroleum industries produce a large amount of leftover from petroleum oil as a residue, which is called petroleum oily sludge (POS). The indiscriminate disposal of inadequately treated oily sludge to the environment is causing a lot of environmental and human health problems. All environmental protection agencies and the experts have classified oily sludge as a hazardous organic waste. Oily sludge is a complex mixture of organic compounds and inorganic metalloids, of which the structure and bioavailability of these compounds resist natural degradation. POS constitutes $50-80 \%$ hydrocarbon, $10-30 \%$ solid material, $20-30 \%$ water and 5-10\% heavy metals ${ }^{3}$. Several physical and chemical methods are being extensively used for the remediation of oily sludge from temporary deposit sites and contaminated environments. However, these methods tend to be expensive and environmentally unfriendly. An alternative is biological methods which can provide an effective and eco-friendly approach. By making use of these kinds of technologies, the content of harmful components is often decreased or eradicated, as well as its negative environmental and health influences can, therefore, be reduced ${ }^{4,5}$.

Nevertheless, because of the recalcitrant character of $\mathrm{POS}^{6}$, the quest for remediation strategies together with the requirement of fulfilling stringent environmental laws and lowering the cost of remediation is a continuing process $^{3}$. The complexity of oily sludge composition of hydrocarbon, heavy metals and others made it hardly bioavailable for microbial degradation ${ }^{5}$. In Malaysia, POS waste falls under the scheduled waste with code SW 311, and about 4,293 tons were generated in 2015 alone (DOE, 2012).

Phytoremediation is one of the strategies of bioremediation, and it uses selected plants to cleanup polluted environment. Plants are more tolerant in general to excessive concentrations of POS compared to microorganisms ${ }^{7}$. Consequently, phytoremediation is potentially a fresh possibility of a much more effective and sustainable answer for the remediation of POS-contaminated soils ${ }^{8}$. Numerous plants have already been recognized to assist in the phytoremediation of areas polluted with petroleum hydrocarbons, and great number of research have identified grasses and legumes due to their reportedly greater tolerance to hydrocarbon and also due to their other beneficial qualities 9 . The plant- microorganisms connection has a tendency to boost the degradation of contaminants in the rhizosphere by way of a symbiotic connection. Plants can promote microbial activity anywhere from 10 to 100 times greater in the rhizosphere through the release of exudates that contain compounds including amino acids, carbohydrates and flavonoids ${ }^{10}$. The secretion of these nutrients-containing exudates offers nitrogen and carbon sources to soil microorganisms. In addition, this process generates an environment that is nutrient-rich in which the activity of microorganisms can be activated. Along with the capability to secrete compounds that can facilitate the activity and growth of rhizospheric microorganisms, plants can furthermore discharge specific enzymes that have the capability to degrade pollutants. The compounding effect results in a more efficient remediation of toxicants, including POS $^{11}$.

Legumes are known to have the edge over non-leguminous plants in the process of phytoremediation due to their capacity for nitrogen fixation ${ }^{12}$ and therefore, do not need to contest with microorganisms as well as other plants for the constrained resources of accessible soil nitrogen. Common desirable characteristics of these plants are the ability to fix nitrogen (a major limiting factor for effective degradation of pollutants) which is strategic to establish nutrient-rich rhizosphere as it is known that areas contaminated with oily sludge have a deficit in the C:N ratio ${ }^{9}$. The legume-bacterial interaction is a synergistic strategy of which leguminous plants provide the microorganisms in the rhizosphere with growing space and essential nutrients, as the microorganisms use their degrading machinery to biodegrade hydrocarbon pollutant in their surroundings ${ }^{13}$. Additionally, rhizo- and endophytic microorganisms, in collaboration with the legume improve the supply of nutrient and growth hormones that can promote plants' growth, and at the same time increase hydrocarbon bioavailability ${ }^{14-17}$. Cajanus cajan (pigeon pea) is also known as Kacang dhal in Malay. It is a very common legume crop in tropical countries. The plant provides an important source of protein to the diet of human. It features a lengthy root system which could endure in various soil types ${ }^{18}$. It can withstand the alterations in $\mathrm{pH}$ over a broad range. In addition, the plant is known to grow at a broad range of temperature from 10 to $35^{\circ} \mathrm{C}^{19}$. In India, this plant is utilized as a multi-purpose plant in the agroforestry industry, in which its many functions include as sources of firewood, manure, food and fodder ${ }^{19}$. Although the plant species utilized in this study has been documented to degrade polluted soil contaminated with spent engine ${ }^{20}$, no prior research has documented its use in the remediation of POS-contaminated soil. In this study, we report for the first time, the phytoremediation of POS in soil using Cajanus cajan.

\section{Materials and Methods}

Experimental setup. The experiment was carried out in the Faculty of Biotechnology and Biomolecular Sciences, Universiti Putra Malaysia. The petroleum oily sludge (POS) used in this study was obtained from a Shell refinery center in Port Dickson, Negeri Sembilan Malaysia in 2014. The POS is in the form of clay mud and black in colour with a $\mathrm{pH}$ of $7.12^{21}$. The soil was collected from an agricultural farm in Universiti Putra Malaysia. The seeds of C. cajan (Pigeon pea) and plastic pots were obtained from a local grocery company.

\section{Experimental Design}

Pot preparation. Soil, which has been previously air-dried and sieved using a $2 \mathrm{~mm}$ sieve was placed in each corresponding pot $(3 \mathrm{~kg})$, and labelled as contaminated rhizosphere $(\mathrm{CR})$, contaminated non-rhizosphere $(\mathrm{CN})$, uncontaminated rhizosphere (UR) and uncontaminated non-rhizosphere (UN) (Fig. 1).

Treatment of soil with POS. POS was added into each pot to the final concentrations of $1 \%, 2 \%, 3 \%, 4 \%$, and $5 \%(\mathrm{w} / \mathrm{w})$ and homogenously mixed. The soil was properly agitated and thoroughly mixed to ensure homogeneity and uniformity of soil to the POS in a fume hood. The pots were allowed to remain undisturbed for one 

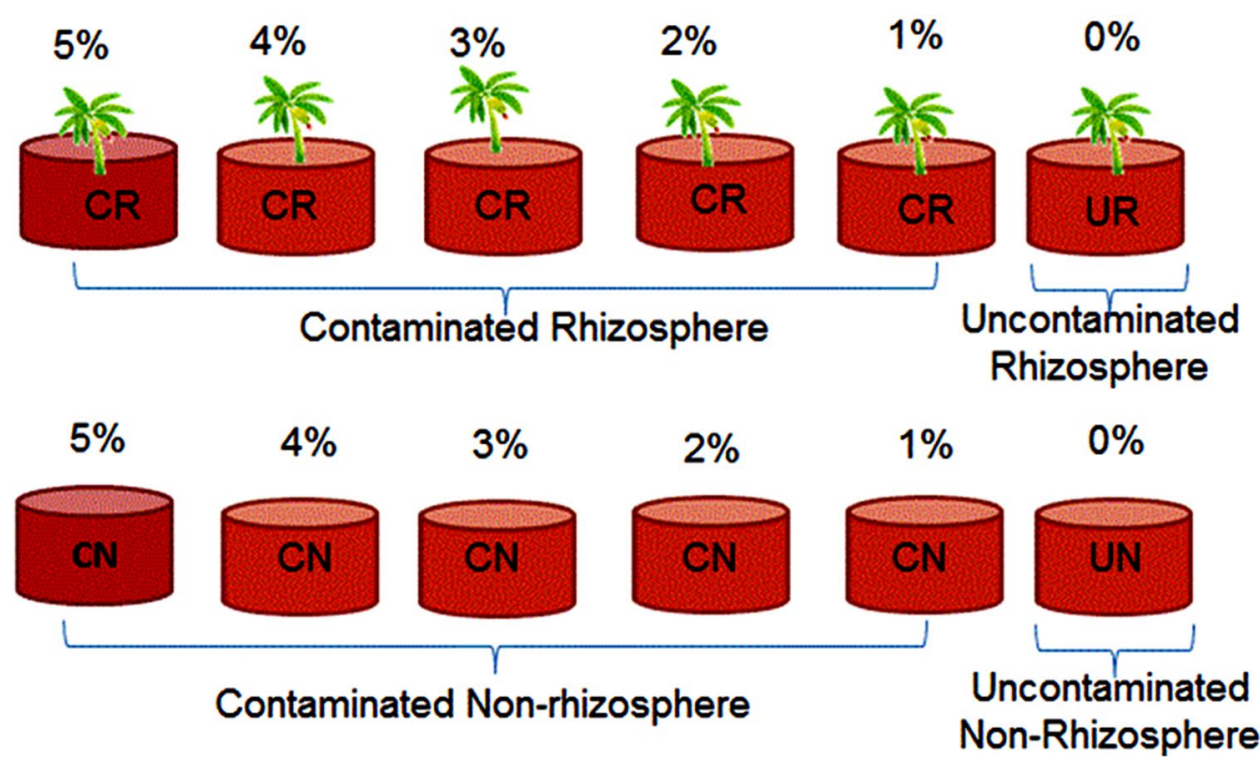

Figure 1. Experimental design showing the various treatments for POS-contaminated soil. The labels CR, CN, UR and UN represent contaminated rhizosphere, contaminated non-rhizosphere, uncontaminated rhizosphere and uncontaminated non-rhizosphere, respectively.

week for the volatilization processes. The soil sample was taken for physicochemical analysis before treatment. After one week, seeds of $C$. cajan were planted accordingly. Three independent experiments were carried out.

\section{Planting of Seeds}

Seed viability test and breaking of dormancy. The viability of the seed of $C$. cajan was tested using the floatation method. The seeds were tested for viability by soaking it in distilled water for $5 \mathrm{~min}$. After that, all floating seeds are sieved out as non-viable and the water was drained immediately from the seeds that sank which are now considered viable seeds. The seeds were then surface sterilized with $10 \%$ hydrogen peroxide solution before planting. The seeds was sown to a depth recommended for C. cajan, which is from 1.5 to $3 \mathrm{~cm}^{22}$. For an excellent establishment of the plants, five seeds were planted in a hole. Likewise, the respective pots were irrigated every day and emergence was observed subsequently. The plants were moderately watered every two days with tap water. The appearance of the plants in response to the presence of POS in soil was monitored to determine if there is any phytotoxicity of POS to the plants.

Microbiological analysis. The media used were Nutrient Agar (NA); for the enumeration and isolation of bacteria, mineral salts media and a modified Bushnell and Haas media the for isolation of hydrocarbon-utilizing bacteria referred to here as oil agar $(\mathrm{OA})$ where diesel oil $(0.1 \% \mathrm{w} / \mathrm{v})$ was used as the carbon source in the medium $^{23}$.

Culture dependent microbial analysis. The bacterial population of the soil samples for $0,30,60$, and 90 days was enumerated by serially diluting $1 \mathrm{~g}$ of soil sample collected from the rhizosphere of $C$. cajan. Suitably diluted samples $\left(10^{-5}, 10^{-6}\right.$ and $\left.10^{-7}\right)$ were transferred into the already prepared media using a dropper pipette, $500 \mu \mathrm{L}$ of each dilution was inoculated on NA and OA which contained $0.1 \% \mathrm{v} / \mathrm{v}$ diesel agar surface ${ }^{23}$. The plates were incubated at $30^{\circ} \mathrm{C}$ for $24 \mathrm{~h}$, for NA, and five days for OA, respectively ${ }^{23}$. The number of viable total heterotrophic rhizobacteria and hydrocarbon-utilizing bacteria in the soil samples was estimated from the number of colonies formed using a colony counter.

Culture-independent microbial analysis. Culture-independent bacterial community in C. cajan rhizosphere after 90 days was determined using metagenomics analysis of the rhizospheric soil collected from the contaminated rhizosphere CR of $3 \%$ oily sludge and contaminated non-rhizosphere $\mathrm{CN}$ of $3 \%$ oily sludge as control.

Soil extraction and PCR amplification. Microbial DNA was extracted from samples in treatments CN3 and CR3 after 90 days using Power soil ${ }^{\circledR}$ DNA Isolation Kits (MOBIO, USA) following the manufacturer's instruction. The marker region of the bacteria was amplified by PCR using a PCR (BioRad Thermal Cycler, United Kingdom) with the following conditions; $95^{\circ} \mathrm{C}$ for $2 \mathrm{~min}$, followed by $25 \mathrm{cycles}$ at $95^{\circ} \mathrm{C}$ for $30 \mathrm{~s}, 55^{\circ} \mathrm{C}$ for $30 \mathrm{~s}$, and $72{ }^{\circ} \mathrm{C}$ for $30 \mathrm{~s}$, and a final extension for $5 \mathrm{~min}$ using the primers sequences $5^{\prime}$ - barcode 2 - (reverse primer sequence) -3 'and 5'-barcode 1- (forward primer sequence) - 3', where the barcode consists of an eight-base sequence that is sample-specific and distinctive to each sample. The PCR reaction was carried out in triplicate $20 \mu \mathrm{L}$-mixtures containing $2 \mu \mathrm{L}$ of $2.5 \mathrm{mM}$ dNTPs, $4 \mu \mathrm{L}$ of $5 \times$ FastPfu buffer, $0.4 \mu \mathrm{L}$ of FastPfu Polymerase, $0.8 \mu \mathrm{L}$ of each primer $(5 \mu \mathrm{M})$ and $10 \mathrm{ng}$ of template DNA. Extraction of amplicons was carried out from a $2 \%$ agarose gel. Purification of the amplicons was carried out utilizing AxyPrep DNA Gel Extraction Kit (Axygen Bioscience, 
Union City, CA, USA) in accordance to the instruction furnished by the manufacturer and quantified using QuantiFluor ${ }^{\mathrm{TM}}$-ST (Promega, USA). Construction of the library was carried out utilizing Linked 'Y' adapter; with adapter dimer removed by utilizing beads and the library was concentrated via PCR and hydroxides utilized in the generation of single-stranded DNA fragments. Sample libraries were then pooled in equimolar concentrations, and paired-end sequenced using the Illumina MiSeq platform $(2 \times 250 / 300 \mathrm{bp})$ according to standard protocols.

\section{Data analysis}

Several criteria were utilized for demultiplexing raw Fasta files and QIIME-based quality-filtration (version 1.9.1). The criteria include overlapped relationship and merging of paired-reads into a single read. The merged reads were then utilized for the clustering of operational taxonomic units (OUT), classification of taxonomy and assessment of community diversity. The software Trimmomatic was utilized for processing sequence reads ${ }^{24}$, and then the reads were assembled utilizing the software Flash ${ }^{25}$ followed up by more analysis using the software MOTHUR v 1.33.026. Alignment of unique sequences was based to the SILVA database with the settings put to default. In addition, removal of chimeric sequences was carried out. Obtained sequences that passed the screening process were then classified using the Ribosomal Database Project naïve Bayesian rRNA classifier at a confidence of $80 \%$. The proportion of sequence identities was calculated at each taxonomic level as the percentage of all sequences classified in that particular sample. Classification of OTUs was based on the similarities of $97 \%$. The software MOTHUR was utilized in the classification of the alpha-diversity indices, which include observed OTUs (Sobs), Ace, Chao, Shannon and InvSimpson indices. PCoA or principal coordinates analysis conducted in $\mathrm{R}$ (Version 3.1.2) was utilized to find the bacterial community structure, which is based on the OTU composition.

\section{Measurement of biodegradation in the soil}

Gravimetric method. Five grams of soil from all treatments were collected and transferred into $100 \mathrm{~mL}$ conical flasks. Then $50 \mathrm{~mL}$ of hexane was added and shaken on a Protech orbital shaker (USA) at $150 \mathrm{rpm}$ for $24 \mathrm{~h}$. The layer separating the solvent with oil and the soil was transferred to a pre-weighted clean conical flask, the sample was left overnight in a fume hood for the evaporation of the solvent, and the amount of residual TPH was gravimetrically determined using the formula.

$$
\% \text { Biodegradation }=\frac{\text { Weight of oil }(\text { control })-\text { Weight of oil }(\text { degraded })}{\text { Weight of oil }(\text { control })} \times 100
$$

\section{Results and Discussion}

Total heterotrophic rhizosphere bacterial count. The total counts for the heterotrophic rhizospheric bacteria (THRB) were enumerated at $0,30,60$ and 90 days of treatments at various concentrations of POS. The result shows that for $1 \%$ POS, the THRB counts for contaminated rhizosphere or CR increased significantly $(\mathrm{p}<0.05)$ but slightly from $125 \times 10^{7}$ to $148 \times 10^{7} \mathrm{CFU} / \mathrm{g}$, while the count for contaminated non-rhizospheric $\mathrm{CN}$ decreased significantly $\left(\mathrm{p}<0.05\right.$ ) from $112 \times 10^{7}$ to $77.3 \times 10^{7} \mathrm{CFU} / \mathrm{g}$, the counts for the uncontaminated rhizosphere UR stayed about the same from $243 \times 10^{7}$ to $241 \times 10^{7} \mathrm{CFU} / \mathrm{g}$ and the counts for the uncontaminated non-rhizosphere UN decreased significantly $\left(\mathrm{p}<0.05\right.$ ) from $202 \times 10^{7}$ to $157 \times 10^{7} \mathrm{CFU} / \mathrm{g}$ (Fig. 2(a)).

The THRB counts for the $2 \%$ POS concentration from 0 to 90 days show a significant $(\mathrm{p}<0.05)$ increase in rhizospheric CR counts from $12.7 \times 10^{7}$ to $144.8 \times 10^{7} \mathrm{CFU} / \mathrm{g}$, no significant change $(\mathrm{p}>0.05)$ to the contaminated non-rhizospheric $\mathrm{CN}$ count (from $66.3 \times 10^{7}$ to $44.7 \times 10^{7} \mathrm{CFU} / \mathrm{g}$ ), no significant change ( $\mathrm{p}>0.05$ ) to the uncontaminated rhizospheric UR count $\left(243 \times 10^{7}\right.$ to $\left.232 \times 10^{7}\right) \mathrm{CFU} / \mathrm{g}$ and also no significant change $(\mathrm{p}>0.05)$ to the uncontaminated non-rhizospheric UN count (from $221 \times 10^{7}$ to $219 \times 10^{7}$ ) CFU/g (Fig. 2(b)).

The THRB counts for the $3 \%$ POS concentration from 0 to 90 days show that the contaminated rhizospheric counts CR were increased but not significant ( $\mathrm{p}>0.05)$ (from $123 \times 10^{7}$ to $145.4 \times 10^{7} \mathrm{CFU} / \mathrm{g}$ ), the contaminated non-rhizospheric $\mathrm{CN}$ counts were not increased significantly $(\mathrm{p}>0.05)$ (from $35.8 \times 10^{7}$ to $\left.31.3 \times 10^{7}\right) \mathrm{CFU} / \mathrm{g}$, the uncontaminated rhizospheric UR counts were increased significantly $(\mathrm{p}<0.05)$ from $152 \times 10^{7}$ to $232 \times 10^{7}$ $\mathrm{CFU} / \mathrm{g}$, and the THRB counts in the uncontaminated non-rhizosphere UN were also not increased significantly $(\mathrm{p}>0.05)\left(\right.$ from $202 \times 10^{7}$ to $\left.219 \times 10^{7}\right) \mathrm{CFU} / \mathrm{g}$ (Fig. $\left.2(\mathrm{c})\right)$.

The THRB counts for the $4 \%$ POS concentration from 0 to 90 days shows that the contaminated rhizospheric count CR was not significantly increased (from $96.7 \times 10^{7}$ to $112 \times 10^{7} \mathrm{CFU} / \mathrm{g}$ ), the contaminated non-rhizospheric $\mathrm{CN}$ counts were decreased significantly $\left(\mathrm{p}<0.05\right.$ ) (from $41.6 \times 10^{7}$ to $23.7 \times 10^{7} \mathrm{CFU} / \mathrm{g}$ ), the uncontaminated rhizospheric UR counts were not significantly $(\mathrm{p}>0.05)$ increased (from $233 \times 10^{7}$ to $232 \times 10^{7}$ CFU/g) and similarly in the uncontaminated non-rhizospheric UN, the bacterial counts were not significantly $\left(\mathrm{p}>0.05\right.$ ) increased (from $200 \times 10^{7}$ to $219 \times 10^{7} \mathrm{CFU} / \mathrm{g}$ ) (Fig. 2(d)). At the highest POS concentration tested $(5 \%)$, there were a decreasing trend or no change in overall for the THRB counts. For example, for the contaminated rhizospheric CR counts, a decrease was observed (from $57.7 \times 10^{7}$ to $45.4 \times 10^{7} \mathrm{CFU} / \mathrm{g}$ ), but this decrease was not significant $(\mathrm{p}>0.05)$, in the contaminated non-rhizosphere $\mathrm{CN}$ counts, a reduction from $23 \times 10^{7}$ to $13.2 \times 10^{7} \mathrm{CFU} / \mathrm{g}$ was observed and this reduction was significant $(\mathrm{p}<0.05)$. In the uncontaminated rhizospheric UR bacterial count, a reduction from $243 \times 10^{7}$ to $223 \times 10^{7} \mathrm{CFU} / \mathrm{g}$ was observed, but similarly, this reduction was not significant $(\mathrm{p}<0.05)$ and finally, in the uncontaminated non-rhizospheric UN counts, there were no significant changes ( $\mathrm{p}>0.05$ ) observed (from $202 \times 10^{7}$ to $200 \times 10^{7} \mathrm{CFU} / \mathrm{g}$ ) (Fig. 2(e)).

In general, the results show a significant $(p<0.05)$ increase in the numbers of THRB counts in the uncontaminated rhizosphere (UR) compared to the uncontaminated non-rhizospheric (UN) bacterial counts. Although the microbial community in the rhizosphere is about 10-100 times higher than that of the non-rhizosphere ${ }^{10}$, the increase in the THRB counts in UR compared to UN as found in this study is marginal. As anticipated, the 

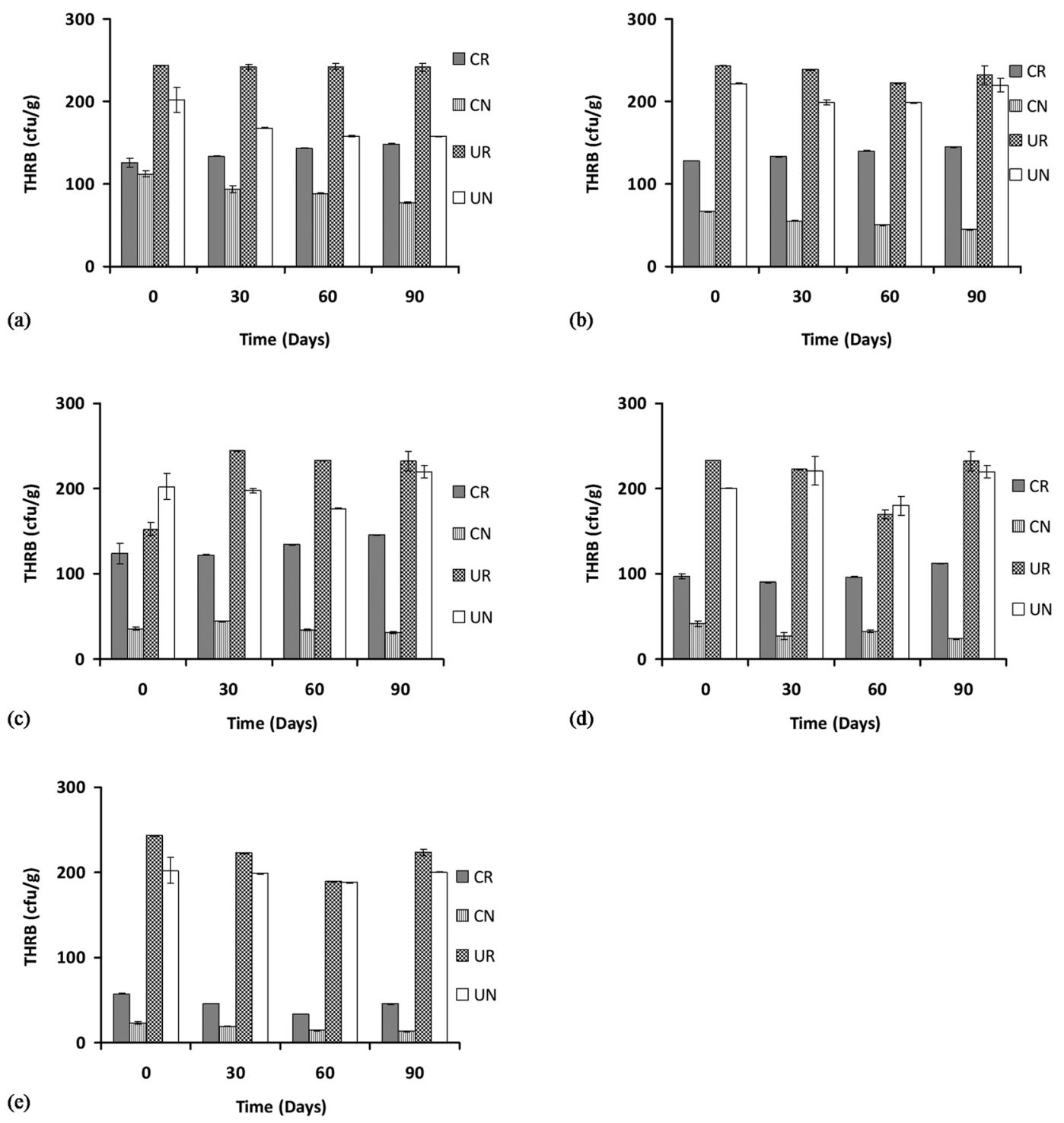

Figure 2. Total heterotrophic rhizospheric bacterial counts at 1,2,3,4, and $5 \%$ concentration of petroleum oily sludge labelled (a), (b), (c), (d) and (e), respectively, under various treatments presented as mean \pm standard deviation $(n=3)$. CR: Contaminated rhizosphere, $\mathrm{CN}$ : Contaminated non-rhizosphere, UR: Uncontaminated rhizosphere, UN: Uncontaminated non-rhizosphere.

presence of the contaminant POS significantly reduces the number of THRB counts in both of the contaminated rhizosphere $(\mathrm{CR})$ and non-rhizosphere $(\mathrm{CN})$ treatments over the uncontaminated treatments (UN and UR). The microbial counts were much more pronounced in the uncontaminated soil than the contaminated soil because of the inhibitory effects of POS to the microorganism in general in the contaminated soil. However, there was a significant increase in the number of bacterial populations over time in the rhizosphere treatments (CR), as there were higher bacterial counts after 90 days of treatment compared to that of 30 days while a decrease in THRB counts was generally observed in CN. This shows that the presence of C. cajan favours the growth of THRB bacteria in the soil as found in other studies ${ }^{22,27}$. The result is also supported by a previous finding ${ }^{28}$, who reported a total decrease in the number of viable heterotrophic bacteria in soil contaminated with oily sludge.

The hydrocarbon utilizing rhizosphere bacteria (HURB) at $1 \%$ POS from 0 to 90 days indicated a significant increase $(\mathrm{p}<0.05)$ in bacterial count in all of the treatments such as in the contaminated rhizosphere CR (from $31.3 \times 10^{7}$ to $131 \times 10^{7} \mathrm{CFU} / \mathrm{g}$ ), in the contaminated non-rhizosphere $\mathrm{CN}$ (from $28 \times 10^{7}$ to $54 \times 10^{7} \mathrm{CFU} / \mathrm{g}$ ), uncontaminated rhizosphere UR (from $30 \times 10^{7}$ to $86 \times 10^{7} \mathrm{CFU} / \mathrm{g}$ ) and in the uncontaminated non-rhizosphere $\mathrm{UN}$ (from $25 \times 10^{7}$ to $58 \times 10^{7} \mathrm{CFU} / \mathrm{g}$ ) (Fig. 3(a)).

In the $2 \%$ POS concentration, the HURB counts from 0 to 90 days show a similar increase in counts where the contaminated rhizosphere CR bacterial counts increased significantly $(\mathrm{p}<0.05)$ from $43 \times 10^{7}$ to $136 \times 10^{7}$ $\mathrm{CFU} / \mathrm{g}$, no significant increase $(\mathrm{p}>0.05)$ in the contaminated non-rhizosphere $\mathrm{CN}$ (from $28 \times 10^{7}$ to $35 \times 10^{7}$ $\mathrm{CFU} / \mathrm{g})$, a significant increase $(\mathrm{p}<0.05)$ for the bacterial count in the uncontaminated rhizosphere UR from 


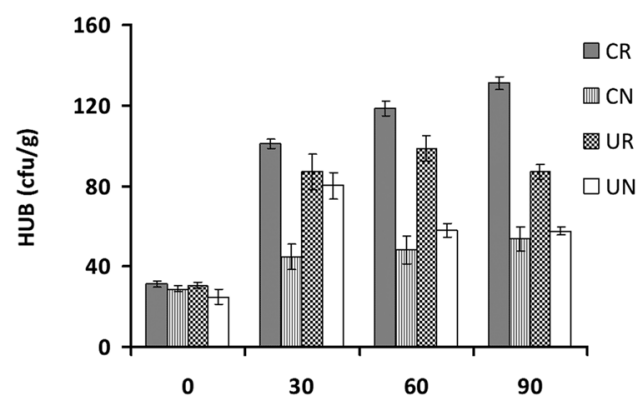

(a)

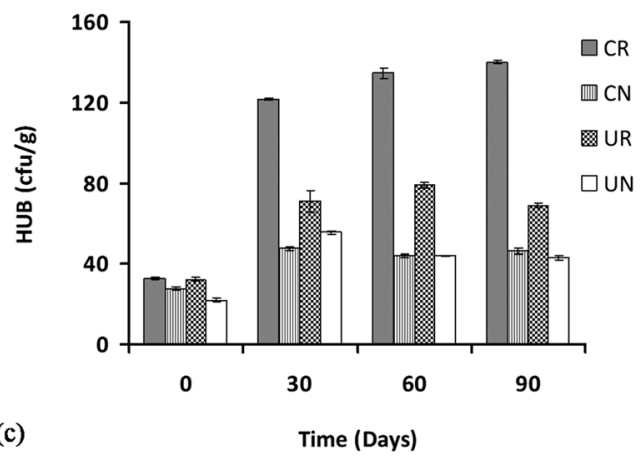

(c)

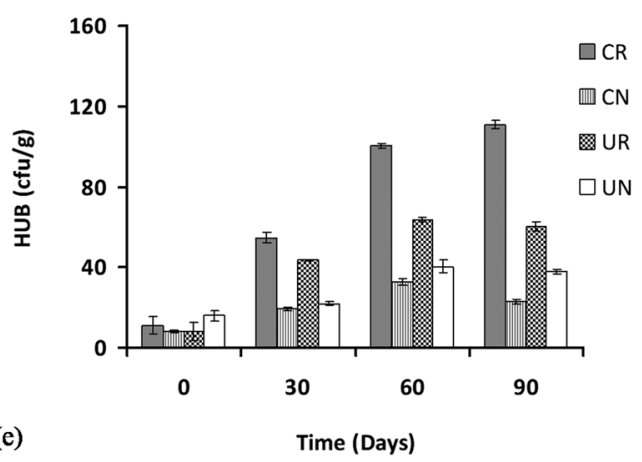

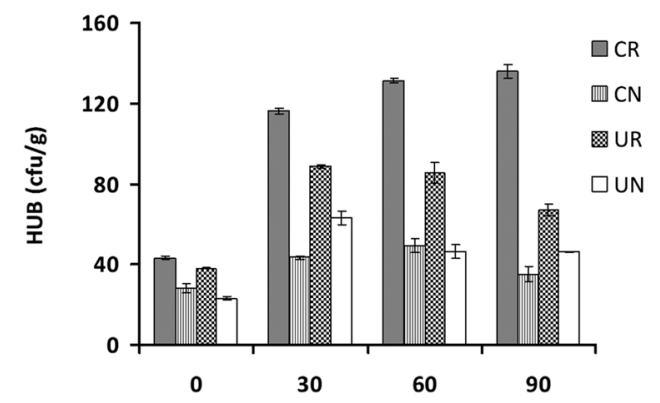

(b)

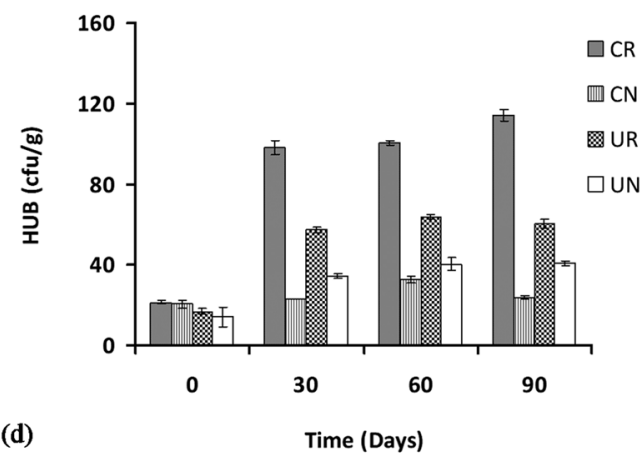

Figure 3. Hydrocarbon-utilizing rhizospheric bacterial counts at 1,2,3,4, and 5\% concentration of petroleum oily sludge labelled (a), (b), (c), (d) and (e), respectively, under various treatments presented as mean \pm standard deviation $(n=3)$. CR: Contaminated rhizosphere, $\mathrm{CN}$ : Contaminated non-rhizosphere, UR: Uncontaminated rhizosphere, UN: Uncontaminated non-rhizosphere.

$38 \times 10^{7}$ to $\left.67 \times 10^{7} \mathrm{CFU} / \mathrm{g}\right)$, and a significant increase $(\mathrm{p}<0.05)$ for the bacterial count in the uncontaminated non-rhizosphere UN as well (from $23 \times 10^{7}$ to $46 \times 10^{7} \mathrm{CFU} / \mathrm{g}$ ) (Fig. 3(b)).

Similarly, for the $3 \%$ POS concentration, the HURB counts increased significantly $(\mathrm{p}<0.05)$ from 0 to 90 days for all treatments such as in the contaminated rhizosphere CR (from $32 \times 10^{7}$ to $140 \times 10^{7} \mathrm{CFU} / \mathrm{g}$ ), in the contaminated non-rhizosphere $\mathrm{CN}$ (from $28 \times 10^{7}$ to $46 \times 10^{7} \mathrm{CFU} / \mathrm{g}$ ), in the uncontaminated rhizosphere UR (from $32 \times 10^{7}$ to $67 \times 10^{7} \mathrm{CFU} / \mathrm{g}$ ) and finally in the uncontaminated non-rhizosphere UN (from $22 \times 10^{7}$ to $43 \times 10^{7}$ CFU/g) (Fig. 3(c)). For the 4\% POS concentration, the counts for HURB for CR were significantly increased from $22 \times 10^{7}$ to $115 \times 10^{7} \mathrm{CFU} / \mathrm{g}$, while no significant increase $(\mathrm{p}>0.05)$ in the contaminated non-rhizosphere $\mathrm{CN}$ was observed from $20 \times 10^{7}$ to $23 \times 10^{7} \mathrm{CFU} / \mathrm{g}$. A significant increase was observed for the uncontaminated rhizosphere UR from $17 \times 10^{7}$ to $60 \times 10^{7} \mathrm{CFU} / \mathrm{g}$ and also for the uncontaminated non-rhizosphere UN from $14 \times 10^{7}$ to $41 \times 10^{7} \mathrm{CFU} / \mathrm{g}$ (Fig. 3(d)). At the highest concentrations of POS tested (5\%) HURB counts increased significantly $(\mathrm{p}<0.05)$ for all treatments. The bacterial counts in the contaminated rhizosphere CR were increased from $11 \times 10^{7}$ to $111 \times 10^{7} \mathrm{CFU} / \mathrm{g}$ ), while the contaminated non-rhizosphere $\mathrm{CN}$ counts were increased from $8 \times 10^{7}$ to $22 \times 10^{7} \mathrm{CFU} / \mathrm{g}$. In the uncontaminated rhizosphere, the UR counts were increased from $8 \times 10^{7}$ to $60 \times 10^{7}$ $\mathrm{CFU} / \mathrm{g}$ ) and in the uncontaminated non-rhizosphere, the UN counts were increased from $16 \times 10^{7}$ to $38.7 \times 10^{7}$ CFU/g (Fig. 3(e)).

Hydrocarbon-utilizing rhizospheric bacterial counts revealed higher numbers in the contaminated rhizosphere (CR) for all of the POS concentrations tested, although the density tends to decrease as the POS concentration was increased. This result is similar to previous finding $s^{29-32}$, which include studies on the phytoremediation 


\begin{tabular}{|c|c|c|c|c|c|c|c|}
\hline \multirow[b]{2}{*}{ Samples } & \multirow[b]{2}{*}{ Reads } & \multicolumn{6}{|l|}{\begin{tabular}{|l|}
0.97 \\
\end{tabular}} \\
\hline & & OTU & Ace & Chao & Coverage & Shannon & InvSimpson \\
\hline $\mathrm{CN} 3$ & 50821 & 512 & 556 & 562 & 0.998 & 3.93 & 13.16 \\
\hline CR3 & 47999 & 650 & 656 & 660 & 0.999 & 5.33 & 66.67 \\
\hline
\end{tabular}

Table 1. Richness and diversity of $16 \mathrm{~s}$ rRNA gene sequences from different treatments. Note: CN3 $=$ Contaminated non-rhizosphere with 3\% oily sludge, CR3 = Contaminated rhizosphere with 3\% oily sludge.

of soil amended with waste lubricating oil with Jatropha curcaa ${ }^{31}$ and Hibiscus cannabinus ${ }^{29}$ where significant increase in hydrocarbon-utilizing bacteria was observed after 30 days of incubation. However, both of these studies require the addition of organic wastes such as brewery spent grain (BSG) and spent mushroom compost (SMC) as additional carbon and nitrogen sources. The results obtained in this work demonstrate the stimulatory effect of rhizosphere to the hydrocarbon-utilizing bacterial population without the need for additional carbon or nitrogen sources.

Considering the complexity of the rhizosphere, a considerable number of microbial communities tend to withstand the toxic effect of the contaminant and are capable of using hydrocarbon as the source of carbon and energy compared to the community in the uncontaminated control. This is similarly reported in a study of epiphytic hydrocarbon-utilizing bacteria where the average number of bacterial density in a given contaminated soil is significantly greater than in the corresponding control, directly indicating that the contaminant is being utilized by the soil bacteria ${ }^{33}$. The results suggest that microbial enumeration is a direct indicative method to prove the response of microorganisms to hydrocarbons ${ }^{34,35}$. For a successful and effective phytoremediation process, the bacterial community in the hydrocarbon-contaminated soil must be well connected to the plant's ability to enhance microbial association in the rhizosphere, resulting in a higher number of hydrocarbon-utilizing bacteria and enhancing their degradative capacity ${ }^{36}$.

Apart from the presence of petroleum oil which serves as the carbon and energy source, the higher population of hydrocarbon-degrading bacteria in the contaminated soil may also be attributed to the additive effect of the C. cajan roots which release organic compounds to further stimulate the degradation and bacterial growth. The increase in HURB counts in the presence of $C$. cajans observed in this study are also observed in several similar studies where higher counts of heterotrophic and oil-degrading bacteria were observed in contaminated rhizospheric soil than in the unplanted contaminated soil ${ }^{8,37}$.

Culture-independent metagenomics analysis. A sum of 59,873 and 59,756 sequences for CN3 and CR3 was found after a sequence optimization method, with an average number of 442.56 and 435.39 sequences for CN3 and CR3, respectively. A sum of 50821 and 47999 reads on CN3 and CR3, respectively, were subsampled from each replicate for further analysis. The calculated bacterial community abundance indices showed an increase in the values for Ace, Cho, Shannon (Shannon-Weaver) and the Simpson's index in CR3 compared to CN3 (Table 1). In phylogeny, OTU is the most commonly applied microbial diversity unit where OTU is clustered with a cutoff of $97 \%$ similarity for the investigation of the abundance of group or species in the microbial community. The difference between CN3 and CR3 was seen in the number of OTU, which were 512 and 650 for CN3 and CR3, respectively, indicating an increase in richness upon the addition of C. cajan. A similar increase in OTU from 48 (control) to 62 (addition of rhizobacteria) is reported during the rhizoremediation of hexachlorobenzene in constructed wetlands ${ }^{38}$. The coverage indices showed a significant difference in the two treatments. The coverage did not change by much in this study. In general, a reduction in coverage rate indicates higher diversity. In a similar study of rhizoremediation of hexachlorobenzene using T. angustifolia rhizosphere and P. australis rhizosphere in constructed wetlands ${ }^{38}$, little reduction in the coverage index was observed for T. angustifolia rhizosphere treatment (from 50 to 47.5 ) while greater reduction in coverage was observed in $P$. australis rhizosphere soil treatment (from 50 to 29) despite both treatments showing nearly equal efficacy in remediating hexachlorobenzene. This may imply that coverage change alone may not be adequate in describing potential remediating ability of rhizodegraders. Of all the indices used in population diversity studies, the robust Shannon and Simpson indices have been recommended in measuring microbial diversity ${ }^{39}$, and it was observed that both of the Simpson's (measured as InvSimpson) and the Shannon values for CR3 were higher than CN3. A change in both indicating an increase in diversity upon the introduction of $C$. cajan into the contaminated soil, which is a common theme seen in several studies involving phytoremediation using legumes ${ }^{11,38,40}$. Both measurements of population were lower in $\mathrm{CN} 3$, which may be due to the toxic effect of the contaminant on the bacterial community. The shift of soil bacterial community organization is also seen in the metagenomics sequences, and the results showed (Fig. 4a) that the contaminated rhizosphere (CR3) shows a diverse community of bacterial phyla, in comparison to the change of the microbial community structure seen in the contaminated non-rhizosphere (CN3). A lower diversity in $\mathrm{CN} 3$ may be the cause of a lower removal rate of petroleum hydrocarbon which has similarly been reported in previous studies ${ }^{40,41}$ where with an increase in the concentration of the contaminant, this results in an increase in the toxicity which reduces the efficiency of microbial degradation. This shows the important role of plant-like C. cajan, which stabilizes the C:N:P ratio for the effective degradation of hydrocarbon by the microbial community ${ }^{22}$. On the other hand, some study reported the inability of plant growth-promoting rhizobacteria to acquire nutrient for growth in severely polluted environments ${ }^{41}$.

The composition and taxonomic analysis of microbiota amplified sequences were categorized into eight phyla (CN3) and ten phyla in (CR3). The overall bacterial composition of the two treatments varied, as the distribution shows a similar variation between the two treatments in the phylum, class, family and genus level distributions, represented by Fig. 4a to d, respectively. This variation in microbial community is also shown by the PCoA plot, 

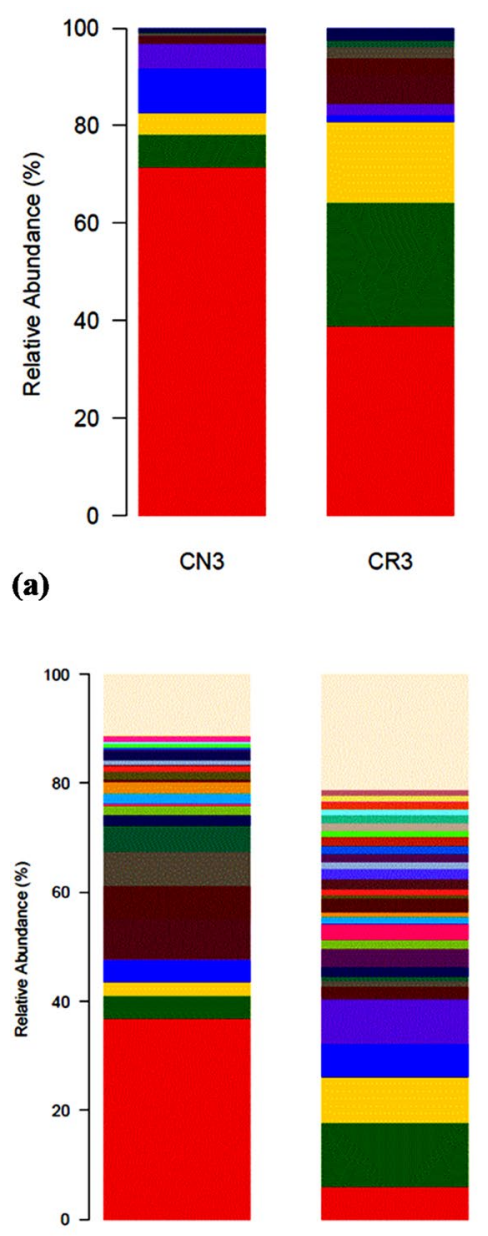

(c)

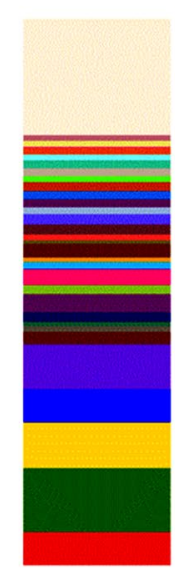

CR3
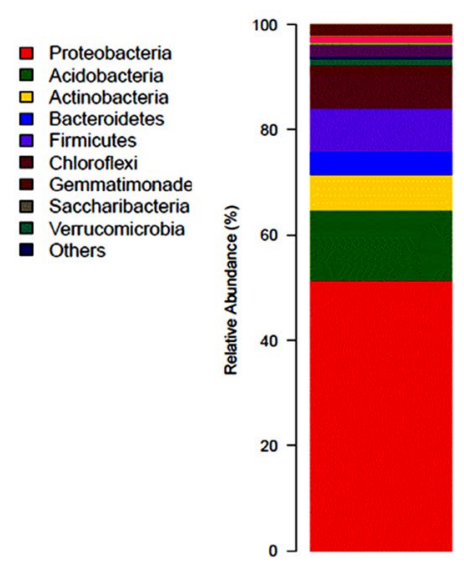

(b)

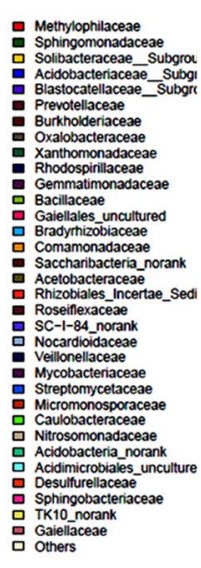

(d)

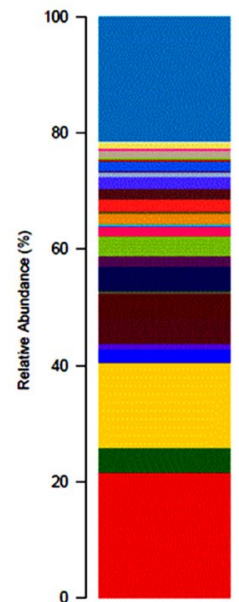

$\mathrm{CN} 3$

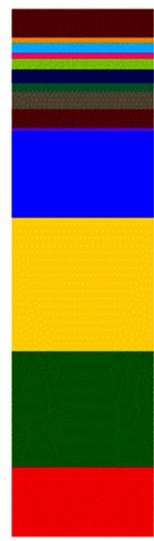

CR3
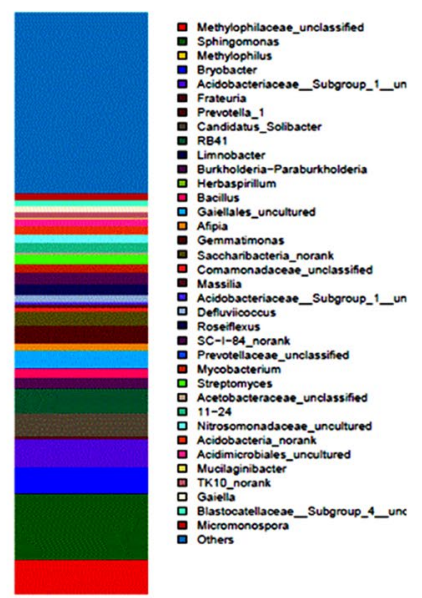

CR3

Figure 4. The relative abundance of bacterial taxa at the phylum (a), class (b), family (c) and genus (d) levels without (CN3) and with (CR3) C. cajan in soils contaminated with 3\% petroleum oily sludge.

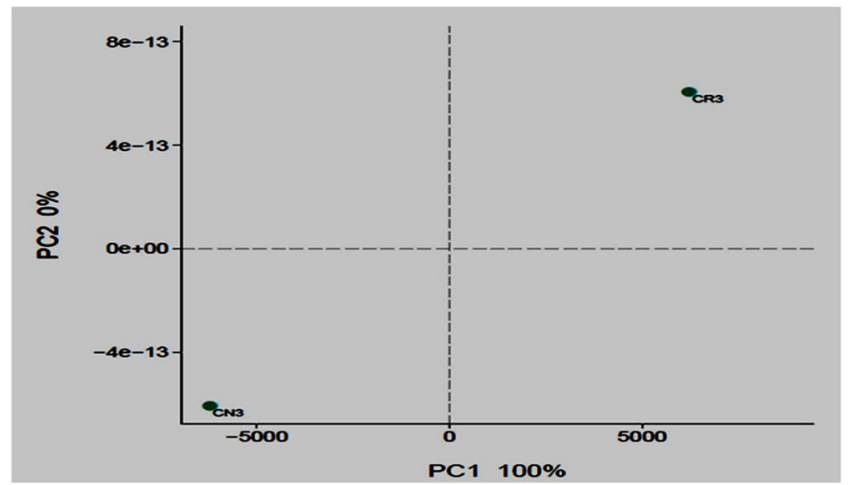

Figure 5. Bacterial $16 \mathrm{~s}$ rRNA community comparison of the different treatments analyzed using principle coordination analysis (PCoA). The proportions of variation by each ordination axis are indicated as percentages in parentheses. CN3 (contaminated non-rhizosphere), CR3 (contaminated rhizosphere).

which revealed community-level differences between the contaminated non-rhizosphere control (CN3) and contaminated rhizosphere (CR3) microbiota (Fig. 5).

The contaminated non-rhizosphere (CN3) shows a trend of bacterial phylum such as Proteobacteria, Actinobacteria, Acidobacteria, Bacteroidetes, Firmicutes, Chloroflexi, Saccharibacteria and some uncategorized group. The contaminated rhizosphere (CR3) shows Actinobacteria, Proteobacteria, Bacteroidetes, Acidobacteria, Firmicutes, Gemmatimonadetes, Saccharibacteria, Chloroflexi and Verrucomicrobia to be the dominant phyla, and 


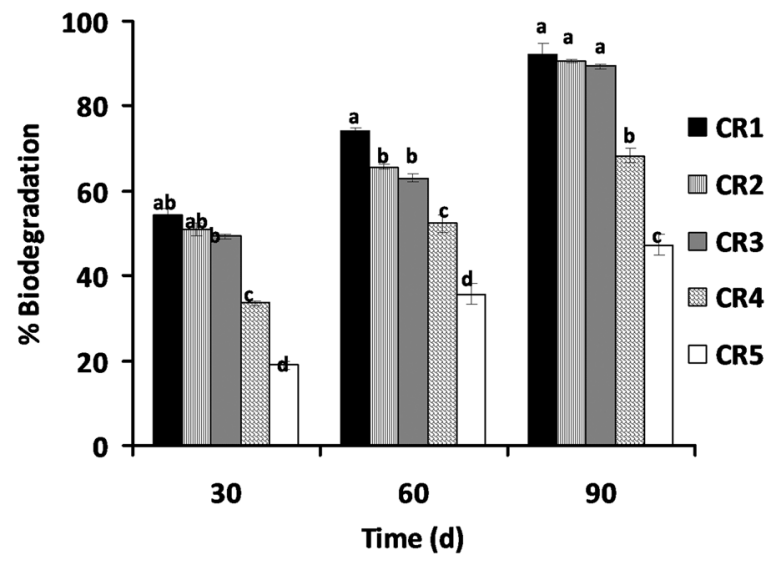

Figure 6. Percentage biodegradation of petroleum oily sludge contaminated soils by C. cajan under different treatments bars (means $+\mathrm{SD}, \mathrm{n}=3$ ) with different letters within treatment days are significantly different based on LSD ( $\mathrm{p}<0.05)$ CR1 to CR5: Contaminated rhizosphere 1 to $5 \%$ oil sludge, respectively.

an unclassified group. In both of the treatments, the phylum Proteobacteria constitute the phylum with higher relative abundance accounting for $>60 \%$ in $\mathrm{CN} 3$ and almost $42 \%$ in CR3. In general, the phylum Proteobacteria dominated the communities of CN3 and CR3 at 70\% and $42 \%$, respectively. In the CN3, the Proteobacteria was dominated by the genus Rhizobium, Sphingomonas, and Herbaspirillum. The two phyla were not observed in $\mathrm{CN} 3$, but the phyla observed were Verrucomicrobia and Gemmatimonadetes. The presence of Verrucomicrobia is an indicator to the rhizospheric effect created by the presence of $C$. cajan as bacteria from this phylum are mostly found inhabiting grasslands and in subsurface soil horizons, where they were habitually the prevailing bacterial phylum ${ }^{42}$. Similarly, Gemmatimonadetes tend to dominant in soil with high rhizosphere activities, although their ecology remains poorly understood, and appear to be the dominant phyla in many soil bacterial communities; with bacteria from the phylum Gemmatimonadetes featuring nearly $2 \%$ of soil bacterial communities. Nevertheless, very little is understood of their ecology as a result of an insufficient study on the occurrence and ecology of this bacterial group ${ }^{43}$. The degradation of petroleum oily sludge hydrocarbons, in general, is accredited to indigenous microorganisms which are found in soil, but the presence of $C$. cajan will stimulate the habitat for the formation of favourable conditions of metabolisms to the microbial communities as demonstrated in this study where the culture-independent metagenomics technique to access a much more in-depth knowledge of the biological processes of petroleum oily sludge degradation during rhizodegradation shows promising results that agrees in principal to what was observed in the experiments.

An assessment at the phylum level identifies the bacteria belonging to the Proteobacteria as the richest community, and the richness was significantly increased. Proteobacteria covers a group of Gram-negative bacteria that have been widely reported to be able to degrade POS $^{41}$.

Biodegradation of petroleum oily sludge in soil. Gravimetric analysis. The result of oily sludge degradation in the soil shows the effectiveness of C. cajan in plant-microbe bioremediation process. The result of the gravimetric analysis shows that almost $50 \%$ biodegradation of the oily sludge was observed at lower concentrations of oily sludge (CR1\%, CR2\% and CR3\%) after 30 days of planting C. cajan (Fig. 6).

A low percentage of biodegradation (19\%) was observed at the highest concentration of oily sludge tested (CR5\%) after 30 days of planting with C. cajan. This may be as a result of inhibition at high concentrations of POS. The biodegradation shows significant $(\mathrm{p}<0.05)$ increase after 60 days of planting of $C$. cajan for all oily sludge concentrations with CR1\%, CR2\%, CR3\% and CR4\% showing 74, 65, 63 and $52 \%$ biodegradation of POS, respectively, while CR5\% was at $37 \%$ which also shows a significant increase albeit at a much lower percentage of degradation. A significant $(\mathrm{p}<0.05)$ increase in biodegradation of POS was shown at the 90 days of the planting of C. cajan where CR1\%, CR2\%, CR3\% and CR4\% show 92, 90, 89 and 68\% degradation, respectively. Likewise, CR5\% had the lowest biodegradation at $47 \%$. This result corresponds to the pattern of many studies observed in different plants, and the biodegradation also varies. In a previous study ${ }^{31}$, they reported that the phytoremediation of soil contaminated with 2.5 and $1 \%$ of spent engine oil using J. curcas at day 180 results in the $56.6 \%$ and $67.3 \%$ biodegradation of waste lubricating oil, respectively. Once the addition of organic waste to J. curcas was carried out, the remediation rapidly increases the removal of 2.5 and $1 \%$ spent engine oil by 89.6 and $96.6 \%$, respectively. The variation is that the plant was stimulated with organic waste to achieve $96 \%$ biodegradation at $1 \%$ spent engine oil concentration whereas in this study, C. cajan being a legume plant, the addition of organic source is not necessary making C. cajan a better phytoremediating plant. Another study in the plant Hibiscus cannabinus for soil contaminated with 2.5 and $1 \%$ used lubricating oil for 90 days show the same pattern of biodegradation where the stimulation of the plant with organic waste resulted in the biodegradation of 86.4 and $91.8 \%$, respectively, while in the unstimulated plant much lower biodegradations were observed at 52.5 and $58.9 \%$, respectively, indicating the need for the addition of organic waste in non-nitrogen fixing plants ${ }^{29}$. Legumes have been shown to independently stimulate biodegradation of various forms of hydrocarbons including poly-aromatic hydrocarbons (PAHs) and their constituents ${ }^{44}$. In all of the phytoremediation studies, legumes are more effective at remediation 
than other non-legume plant species tested ${ }^{15,17,20,44-50}$. In some studies, the biodegradation of legume was reported to be lower at the beginning of the experiment but significantly increases as the experiments progresses ${ }^{44}$.

\section{Data availability}

All data generated or analyzed during this study are included in this published article (and its Supplementary Information files).

Received: 28 April 2019; Accepted: 12 February 2020;

Published online: 05 March 2020

\section{References}

1. Sabullah, M. K. et al. Bioremediation of Hydrocarbon: A Mini Review. J. Biochem. Microbiol. Biotechnol. 6, 1-6 (2018).

2. Zahaba, M. Luminescent bacterial testing for monitoring hydrocarbon bioremediation - a review. J. Biochem. Microbiol. Biotechnol. 3, 13-20 (2015)

3. Islam, B. Petroleum sludge, its treatment and disposal: A review. Int. J. Chem. Sci. 13, 1584-1602 (2015).

4. Prakash, V., Saxena, S., Sharma, A., Singh, S. \& Singh, S. Treatment of oil sludge contamination by composting. J. Bioremediation Biodegrad. 06, (2015).

5. Hu, G., Li, J. \& Zeng, G. Recent development in the treatment of oily sludge from petroleum industry: A review. J. Hazard. Mater. 261, 470-490 (2013).

6. Ubani, O., Atagana, I. H. \& Thantsha, S. M. Biological degradation of oil sludge: A review of the current state of development. Afr. J. Biotechnol. 12, 6544-6567 (2013).

7. Aisien, F. A., Aisien, E. T. \& Oboh, I. O. Phytoremediation of petroleum- polluted soils. in Management of Environmental Contaminants (eds. Ansari, A. A., Gill, S. S., Gill, R., Lanza, G. R. \& Newman, L.) vol. 1 243-252 (Springer International Publishing, 2015).

8. Muratova, A. Y., Dmitrieva, T. V., Panchenko, L. V. \& Turkovskaya, O. V. Phytoremediation of oil-sludge-contaminated soil. Int. J. Phytoremediation 10, 486-502 (2008).

9. Vázquez-Luna, D. Biological indices of toxicity in tropical legumes grown in oil-contaminated soil. Ecol. Indic. 53, 43-48 (2015)

10. Weller, D. M. \& Thomashow, L. S. Current Challenges in Introducing Beneficial Microorganisms into the Rhizosphere. in Molecular Ecology of Rhizosphere Microorganisms 1-18 (John Wiley \& Sons, Ltd, 2007). https://doi.org/10.1002/9783527615810.ch1.

11. Liu, W. et al. Rhizobacteria (Pseudomonas sp. SB) assist phytoremediation of oily-sludge-contaminated soil by tall fescue (Testuca arundinacea L.). Plant Soil 371, 533-542 (2013).

12. Ugrinovic, M. et al. Intercropped red beet and radish with green bean affected microbial communities and nodulation by indigenous rhizobia. Agric. Food Sci. 173-185 (2014).

13. Bauddha, K., Singh, K., Singh, B. \& Singh, R. Ricinus communis: A robust plant for bio-energy and phytoremediation of toxic metals from contaminated soil. Ecol. Eng. Jo 84, 640-652 (2015).

14. Alaru, M. et al. Crop yields and supply of nitrogen compared in conventional and organic farming systems. Agric. Food Sci. 317-326 (2014).

15. Remigi, P., Zhu, J., Young, J. P. \& Masson-Boivin, C. Symbiosis within symbiosis: Evolving nitrogen-fixing legume symbionts. Trends Microbiol. 24, 63-75 (2016).

16. Jerez, C. J. A. \& Romero, R. M. Evaluation of Cajanus cajan (pigeon pea) for phytoremediation of landfill leachate containing chromium and lead. Int. J. Phytoremediation 6514, 00-00 (2016).

17. Saadani, O. et al. In situ phytostabilisation capacity of three legumes and their associated Plant Growth Promoting Bacteria (PGPBs) in mine tailings of northern Tunisia. Ecotoxicol. Environ. Saf. 130, 263-269 (2016).

18. Lim, T. K. Cajanus cajan. Edible Medicinal And Non-Medicinal Plants: Volume 2, Fruits (ed. Lim, T. K.) 549-568 (Springer Netherlands, 2012). https://doi.org/10.1007/978-94-007-1764-0_70.

19. Singh, N. K. et al. The first draft of the pigeonpea genome sequence. J. Plant Biochem. Biotechnol. 21, 98-112 (2012)

20. Ismail, H. Y., Ijah, U. J. J., Riskuwa, M. L., Allamin, I. A. \& Isah, M. A. Assessment of phytoremediation potentials of legumes in spent engine oil contaminated soil. Eur. J. Environ. Saf. Sci. 2, 59-64 (2014).

21. Shamsul Harumain, Z. A. Biodegradation of petroleum sludge by Methylobacterium sp. (Universiti Putra Malaysia, 2012).

22. Sharma, R. et al. Survival, efficacy and rhizospheric effects of bacterial inoculants on Cajanus cajan. Agric. Ecosyst. Environ. 240, 244-252 (2017).

23. Chikere, C. B., Okpokwasili, G. C. \& Ichiakor, O. Characterization of hydrocarbon utilizing bacteria in tropical marine sediments. J. Biotechnol. 8, 2541-2544 (2009)

24. Bogler, A. M., Lohse, M. \& Usadel, B. Trimmomatric: a flexible trimmer for Illumina sequence data. Bioinformatics 30, 2114-2120 (2014).

25. Magoc, T. \& Salzberg, S. L. FLASH: fast length adjustment of short reads to improve genome assemblies. Bioinformatics 27, 2957-2963 (2011).

26. Kozich, J. J., Westcott, S. L., Baxter, N. T., Highlander, S. K. \& Schloss, P. D. Development of a dual-index sequencing strategy and curation pipeline for analyzing amplicon sequence data on the MiSeq Illumina sequencing platform. Appl. Environ. Microbiol. 79, $5112-5120$ (2013).

27. Sangeetha, J. \& Thangadurai, D. Effect of biologically treated petroleum sludge on seed germination and seedling growth of vigna unguiculata (1.) walp. (fabaceae). Braz. Arch. Biol. Technol. 57, 427-433 (2014).

28. Mansur, A. A. et al. Assessing the hydrocarbon degrading potential of indigenous bacteria isolated from crude oil tank bottom sludge and hydrocarbon-contaminated soil of Azzawiya oil refinery, Libya. Environ. Sci. Pollut. Res. 21, 10725-10735 (2014).

29. Abioye, O. P., Agamuthu, P. \& Abdul Aziz, A. R. Phytotreatment of soil contaminated with used lubricating oil using Hibiscus cannabinus. Biodegradation 23, 277-286 (2012).

30. Abioye, O. P., Agamuthu, P., Abdul Aziz, A. R., Afzal, M. \& Khan, Q. M. Microbe assisted phytoremediation of oil sludge and role of amendments: a mesocosm study. J. Environ. Manage. 12, 1-8 (2012).

31. Agamuthu, P., Abioye, O. P. \& Aziz, A. A. Phytoremediation of soil contaminated with used lubricating oil using Jatropha curcas. J. Hazard. Mater. 179, 891-894 (2010).

32. Agnello, A. C., Huguenot, D., van Hullebusch, E. D. \& Esposito, G. Citric acid-and Tween ${ }^{\circledR} 80$-assisted phytoremediation of a cocontaminated soil: alfalfa (Medicago sativa L.) performance and remediation potential. Environ. Sci. Pollut. Res. 9215-9226 (2016) https://doi.org/10.1007/s11356-015-5972-7.

33. Diab, A. \& Badry, K. A. Biodegradation of PAH compounds in the rhizosphere of Tamarix nilotica: A salt tolerant wild plant. J. Am. Sci. 7, 115-124 (2011)

34. Ukaegbu-Obi, K. M. \& Mbakwem-Aniebo, C. C. Bioremediation potentials of bacteria isolated from rhizosphere of some plants of oil contaminated soil of Niger Delta. J. Appl. Environ. Microbiol. 2, 194-197 (2014).

35. Ali, N., Sorkhoh, N., Salamah, S., Eliyas, M. \& Radwan, S. The potential of epiphytic hydrocarbon-utilizing bacteria on legume leaves for attenuation of atmospheric hydrocarbon pollutants. J. Environ. Manage. 93, 113-120 (2012). 
36. Koolivand, A. et al. Degradation of petroleum hydrocarbons from bottom sludge of crude oil storage tanks using in-vessel composting followed by oxidation with hydrogen peroxide and Fenton. J. Mater. Cycles Waste Manag. 15, 321-327 (2013).

37. Basumatary, B., Saikia, R. \& Bordoloi, S. Phytoremediation of crude oil contaminated soil using nut grass, Cyperus rotundus. J Env. Biol 33, 891-896 (2012).

38. Zhang, C. et al. Structure and function of the bacterial communities during rhizoremediation of hexachlorobenzene in constructed wetlands. Environ. Sci. Pollut. Res. 24, 11483-11492 (2017).

39. Kim, B.-R. et al. Deciphering diversity indices for a better understanding of microbial communities. J. Microbiol. Biotechnol. 27, 2089-2093 (2017).

40. Tu, C. et al. Rhizoremediation of a dioxin-like PCB polluted soil by alfalfa: Dynamic characterization at temporal and spatial scale. Chemosphere 189, 517-524 (2017).

41. Hou, J. et al. PGPR enhanced phytoremediation of petroleum contaminated soil and rhizosphere microbial community response. Chemosphere 138, 592-598 (2015).

42. Bergmann, G. T. et al. The under-recognized dominance of Verrucomicrobia in soil bacterial communities. Soil Biol. Biochem. 43, 1450-1455 (2012).

43. Debruyn, J. M., Nixon, L. T., Fawaz, M. N., Johnson, A. M. \& Radosevich, M. Global biogeography and quantitative seasonal dynamics of Gemmatimonadetes in soil. Appl. Environ. Microbiol. 77, 6295-6300 (2011).

44. Halla, J., Soole, K. \& Bentham, R. Hydrocarbon phytoremediation in the family Fabacea - A Review. Int. J. Phytoremediation 13, $317-332(2011)$

45. Ji, Z. J. et al. Competition between rhizobia under different environmental conditions affects the nodulation of a legume. Syst. Appl. Microbiol. 40, 114-119 (2017).

46. Sugiyama, A. \& Yazaki, K. Root exudates of legume plants and their involvement in interactions with soil microbes. Signal. Commun. Plants 12, 27-49 (2012).

47. Reichman, S. M. The potential use of the legume-rhizobium symbiosis for the remediation of arsenic contaminated sites. Soil Biol. Biochem. 39, 2587-2593 (2007).

48. Hao, X. et al. Phytoremediation of heavy and transition metals aided by legume-rhizobia symbiosis. Int. J. Phytoremediation 16, 179-202 (2014).

49. Sánchez-Pardo, B. \& Zornoza, P. Mitigation of $\mathrm{Cu}$ stress by legume-Rhizobium symbiosis in white lupin and soybean plants. Ecotoxicol. Environ. Saf. 102, 1-5 (2014).

50. Piechalak, A., Tomaszewska, B., Baralkiewicz, D. \& Malecka, A. Accumulation and detoxification of lead ions in legumes. Phytochemistry 60, 153-162 (2002).

\section{Acknowledgements}

This project was supported by the Putra-IPS grants GP-IPS/2017/9517500 (Rhizodegradation of petroleum oily sludge contaminated soil by hetero-rhizospheric bacteria from Cajanus cajan (Pigeon pea)).

\section{Author contributions}

I.A.A., S.A.A, Y.S. and S.R.S.A. designed research. I.A.A. conducted the experiments. N.A.Y., M.I.E.H. and Y.S analyzed the data. I.A.A. wrote the main manuscript and prepared figures and tables. All authors have reviewed the manuscript.

\section{Competing interests}

The authors declare no competing interests.

\section{Additional information}

Supplementary information is available for this paper at https://doi.org/10.1038/s41598-020-60668-1.

Correspondence and requests for materials should be addressed to Y.S.

Reprints and permissions information is available at www.nature.com/reprints.

Publisher's note Springer Nature remains neutral with regard to jurisdictional claims in published maps and institutional affiliations.

(c) (i) Open Access This article is licensed under a Creative Commons Attribution 4.0 International License, which permits use, sharing, adaptation, distribution and reproduction in any medium or format, as long as you give appropriate credit to the original author(s) and the source, provide a link to the Creative Commons license, and indicate if changes were made. The images or other third party material in this article are included in the article's Creative Commons license, unless indicated otherwise in a credit line to the material. If material is not included in the article's Creative Commons license and your intended use is not permitted by statutory regulation or exceeds the permitted use, you will need to obtain permission directly from the copyright holder. To view a copy of this license, visit http://creativecommons.org/licenses/by/4.0/.

(C) The Author(s) 2020 